\title{
Reduction of Pollutant from Bleached Kraft Pulp Mills by the Process Conversion to ECF Bleaching (Part III)
}

\section{-Reductions of Emission and Generation of Dioxins in Bleached} Filtrates, Bleached Pulps and Whole Mill Effluents-

\section{Kazumasa Toyota $^{* 2, a)}$, Reiji Kaneko ${ }^{\text {a) }}$, Kazuhito Kawasaki} and Katsuichi Terada

Japan Pulp \& Paper Research Institute, Inc. ${ }^{* 1}$

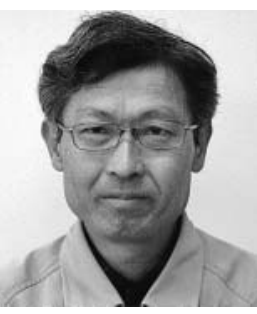

Kazumasa Toyota

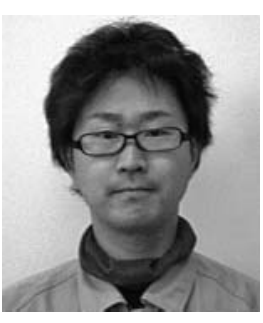

Kazuhito Kawasaki

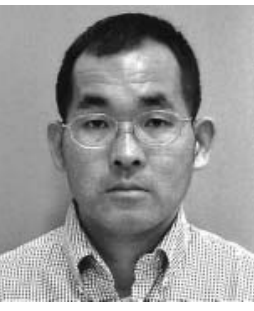

Reiji Kaneko

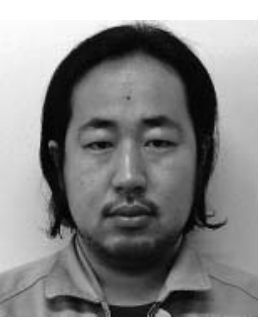

Katsuichi Terada

\begin{abstract}
We have reported effect of elemental chlorine free (ECF) bleaching for mill effluent in previous paper. As a result of change chemical substances for pulp bleach, the amounts of absorbable organic halogen (AOX) and extractable organic halogen (EOX) decrease to significant lower level when substitution of chlorine dioxide is used. A more recent survey for polychlorinated dioxins and dibenzofurans (Dioxins) are also studied.

Effects of ECF bleaching on reduction of dioxins were investigated for 14 bleached kraft pulp mills in Japan, which is a largest study in domestic. Dioxins concentrations in the bleached pulps, bleached filtrates, and whole mill effluents before and after the ECF conversions were measured and compared.

After the ECF bleaching process was introduced, the generation of dioxins was dramatically suppressed in all of the mills, and the dioxin levels were decreased by less than 1/50 after the ECF conversion. Similarly, the concentrations of dioxins of the bleached filtrates after the conversion also decreased by less than $1 / 20$, strongly indicating that the shift of bleaching process to the ECF bleaching effectively suppresses the generation of dioxins.
\end{abstract}

\footnotetext{
${ }^{* 1}$ 5-13-11 Tokodai, Tsukuba-shi, Ibaraki 300-2635, Japan

${ }^{* 2}$ E-mail : 0085011@np-g.com

${ }^{a)}$ Current address : NPi Research Laboratory, Nippon Paper Industries Co., Ltd./5-21-1 Oji, Kita-ku, Tokyo 114-0002, Japan
} 
The dioxin levels in the whole mill effluents after ECF conversion of the mills were below $1 \mathrm{pg}-\mathrm{TEQ} / \mathrm{L}$ that is the environmental standard in Japan. Furthermore, some isomers of dioxins specifically generated by chlorine bleaching process were not detected in the whole mill effluents, confirming that the ECF conversion effectively suppresses the emission of dioxins into the environment.

Already in two companies 14 mills, generation of dioxins from bleaching processes are not ditected. Further, most emissions of dioxins from effluents also became an excellent levels.

Keywords : pulp, ECF, dioxins

\section{Introduction}

The obvious deterioration of the biological diversity in the Baltic Sea was recognized at the end of the $1960 \mathrm{~s}$. The Convention on the Protection of the Marine Environment of the Baltic Sea Area was adopted in the Scandinavian countries in 1974. Consequently, the coastal countries along the Baltic Sea have initiated comprehensive efforts for the protection of the marine environment. Dioxins came to be reported as one of chemical pollutants in the late 1980 s. In the International Symposium on Halogenated Environmental Organic Pollutants and POPs held in Umeå, Sweden in $1988^{11}$, Rappe et al. reported the formation of dioxins originating from chlorine bleaching. The results of the investigation of dioxins in 104 pulp and paper mills were also reported in $\mathrm{USA}^{2)}$. To respond to these situations and remove the origin of dioxins, the conversion of chlorine bleaching to the Elemental Chlorine-free (ECF) and Totally Chlorine-free (TCF) bleachings, where chlorine is not used, was completed in the Scandinavian countries in 1994.

In Japan, dioxins were detected from flathead mullets captured at the mouth of the Kinsei river flowing through Kawanoe-shi, Ehime-ken in October 1990. These dioxins were presumed to originate from chlorine bleaching because of the pattern of their isomers detected ${ }^{3}$. The formation of dioxins is suppressed, when the amount of chlorine used in pulp bleaching process is small ${ }^{4}$. Japanese pulp and paper industry made efforts for introducing oxygen delignification, reinforcing effluent treatment, etc. to reduce the emission of organic chlorine compounds produced in chlorine bleaching process, applying the Absorbable Organic Halogens (AOX), which shows total amount of organic chlorine compounds, as an index. The self-imposed standard of AOX in total effluent, $1.5 \mathrm{~kg} /$ ton pulp, was achieved in $1993^{5,6)}$.

Dioxins do not indicate a chemical species but are a general term for compounds, such as polychlorinated dibenzo$p^{- \text {dioxin }}(\mathrm{PCDD})$, polychlorinated dibenzofuran (PCDF), dioxin-like polychlorinated biphenyls (DL-PCB), etc., all of which have the toxicity similar to that of $2,3,7,8$-tetrachlorodibenzo- $p^{- \text {dioxin }}(2,3,7,8$-TeCDD). Concerning the toxicity of dioxins, WHO additionally fixed the toxic equivalent factor (TEF), which is standardized on the toxicity of 2, 3, 7, 8-TeCDD, for 13 kinds of DL-PCB in 1994. In 1997, 2, 3, 7, 8-TeCDD was classified as a carcinogen for humans in the review of carcinogenicity. To date, 29 kinds of dioxins have been known to have the toxicity.

It was reported in the late $1990 \mathrm{~s}$ that the amount of dioxins discharged with emission gas was large especially in Japan. Consequently, the enforcement ordinance for the Air Pollution Control Law was amended in August 1997. The new domestic standard was fixed for emission gas, and came into operation on December $1^{\text {st }} 1997$. Then, the Law Concerning Special Measures Against Dioxins was enforced on January $15^{\text {th }} 2000$, and consequently, pulp mills with bleaching facility were designated as specified facilities. The regulation for water quality of effluent, $10 \mathrm{pg}-$ TEQ/L (TEQ : toxicity equivalency quantity), was fixed at these specified mills.

From consideration to the influence on the environment, the conversion to ECF bleaching also came to be promoted in Japanese pulp and paper industry in around 2000. About $90 \%$ of Japanese bleached pulp is currently produced by ECF bleaching. It was reported that even in ECF bleaching organic chlorine compounds were produced by the presence of tiny amounts of chlorine and hypochlorite contaminated when some types of chlorine dioxide generator were used in the early stage of the conversion to ECF bleaching ${ }^{7}$. It was also reported that dioxins detected in mill effluent consist not only of those originating from chlorine bleaching but also those from emission gas and agricultural chemicals contaminated in process water for mill use $e^{8}$. It is currently considered that the formation of organic chlorine compounds, such as chloroform and dioxins, is further suppressed by the advancement of the improvement of bleaching facilities.

Related to the enforcement of the Cluster Rule in North America, it was comprehensively reported how were the situations of dioxins emission from lots of mills after the conversion to ECF bleaching ${ }^{9}$, although dioxins emission from each individual mill before the conversion to ECF bleaching was not compared with that after the conversion on a large scale. The dioxins formation in some Japa- 
nese mills before the conversion to ECF bleaching was compared with that after the conversion ${ }^{10,11}$.

We previously reported that the conversion to ECF bleaching in mills belonging to Oji Paper Co. Ltd. and Nippon Paper Industries Co. Ltd. greatly reduced the EOX (Extractable Organohalogens) and AOX (Absorbable Organic Halogens) as the total amounts of chlorinated compounds as well as the amounts of the formation of chloroform and chlorophenols as individual compounds ${ }^{5,6}$. In this paper, the formation and emission of dioxins from these mills before and after the conversion to ECF bleaching are further discussed.

\section{Experimental}

\subsection{Mills subjected to the investigation}

In 23 bleaching lines of 17 mills belonging to Oji Paper Co. Ltd. and Nippon Paper industries Co. Ltd., where the KP bleaching processes were converted to ECF bleaching from 2000 thorough 2006, the total effluents, bleached pulps, and process waters for bleaching were extracted and analyzed. Among these, the total effluents from 14 mills and the process waters for bleaching together with the kraft pulps obtained from 18 bleaching lines were chosen in this paper, and the concentration and amount of dioxins in these samples were reported. In the samples obtained from these 14 mills and 18 bleaching lines, the data before the conversion of ECF bleaching could sufficiently be compared with those after the conversion.

Unbleached pulp was delignified by oxygen followed by chlorine etc. in general pulp bleaching processes. Dioxins generated in these processes were distributed to process water and bleached pulp (Fig. 1). Therefore, process water together with bleached pulp was withdrawn from the 1 st bleaching stage (This was the process water for chlorine bleaching stage and the effluent from chlorine dioxide or ozone bleaching stage before and after the conversion to ECF bleaching, respectively.) and $2^{\text {nd }}$ bleaching stage (This was the process water for alkaline extraction stage.) of each bleaching line. Dioxins detected in bleached pulps were treated as a part of the amount of generated dioxins.

\subsection{Analysis of dioxins}

Concentration and amount of dioxins in total effluent and process water for bleaching were analyzed following the method of JIS K 0312. In the analysis of unbleached pulp, the method was partly modified, and pulp samples were additionally extracted with ethanol under reflux conditions. The minimum amounts were fixed at 0.5 and 0.15 $\mathrm{pg}-\mathrm{TEQ} / \mathrm{L}$ for the quantification and detection of $2,3,7,8^{-}$ TeCDD, respectively, in the analysis of total effluent. These values were 1.0 and $0.3 \mathrm{pg}-\mathrm{TEQ} / \mathrm{L}$, respectively, in the analysis of process water for bleaching, and 0.05 and $0.015 \mathrm{pg}-\mathrm{TEQ} / \mathrm{g}$, respectively, in the analysis of bleached pulp.

Concerning the toxic equivalent factor (TEQ), WHO : TEF (1998) was applied in this study in spite of the presence of the already opened WHO : TEF (2006), because the data before the conversion to ECF bleaching (2000 2006) should be treated consistently with those after the conversion (2002 2008). According to the method of JIS $\mathrm{K} 0312$, only TEQ values equal or more than the minimum limit for the quantification are adopted. However, this method underestimated the TEQ values in this study, because lots of the TEQ values obtained in this study were smaller than the minimum limit for the quantification and equal or larger than the minimum limit for the detection. Therefore, all the TEQ values equal or more than the minimum limit for the detection were adopted in this study, and those less than the minimum limit for the detection were treated as 0 .

\subsection{Analysis of the origin of dioxins}

Fig. 2 shows the origins and principal isomers of dioxins. It is considered that the dioxins characteristically originating from chlorine bleaching are strongly toxic $2,3,7,8^{-}$ TeCDD, 2, 3, 7, 8-TeCDF, and non-toxic 1, 2, 7, 8-TeCDF ${ }^{12}$. An agricultural chemical, pentachlorophenol (PCP), contained in process water for mill use is known to exist together with octachlorodibenzo-p-dioxin (OCDD) and 1, 2, 3, 4, 6, 7, 8-heptachlorodibenzo-p-dioxin (1, 2, 3, 4, 6, 7, 8 $-\mathrm{HpCDD})^{7}$. When chloronitrophen (CNP) is similarly de-
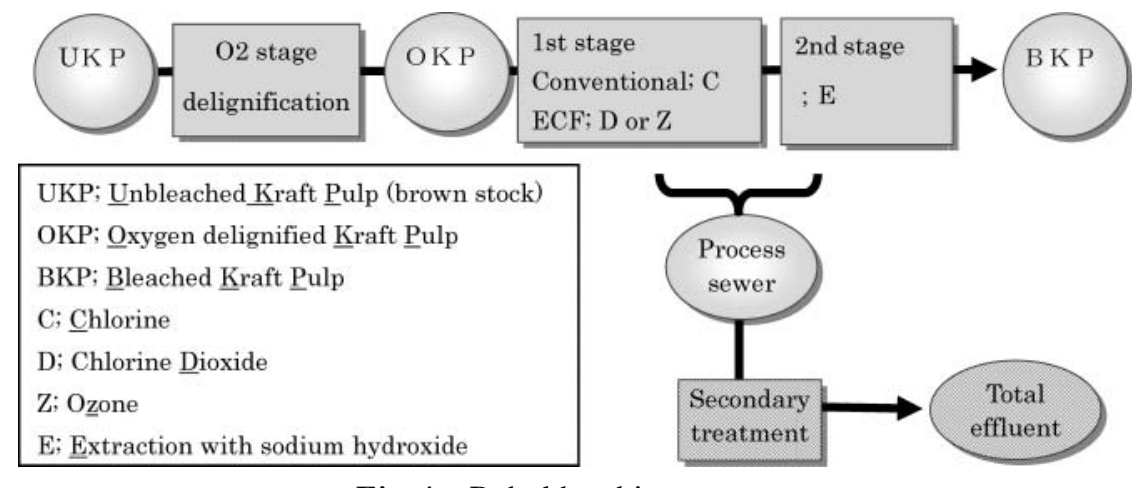

Fig. 1 Pulp bleaching process 


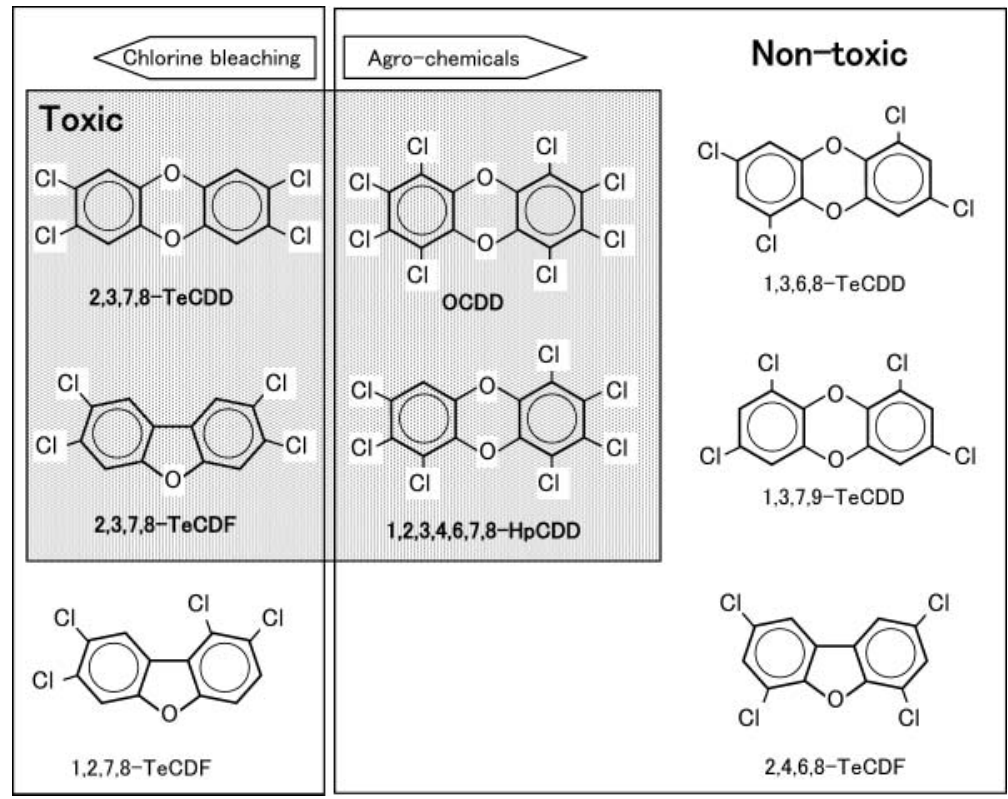

Fig. 2 Major dioxin isomers

tected as an agricultural chemical, isomers of dioxins, such as 1, 3, 6, 8-TeCDD, 1, 3, 7, 9-TeCDD, and 2, 4, 6, 8-TeCDF, are detected together ${ }^{13}$. When combustion facility in mill is the origin, various types of dioxins isomers are detected ${ }^{14)}$.

It has been trialed to estimate the origin of dioxins based on these characteristic compositions of dioxin isomers described above. For instance, it was reported that the origin was estimated using a multivariate statistic, the chemical mass balance (CMB) method ${ }^{15)}$. This method had the problem that the origin could precisely be estimated only when all the origins as well as the composition of dioxin isomers generated from each origin were clearly known and otherwise the analysis was impossible. Thus, it was examined how to estimate the proportion of the amount of 2, 3, 7, 8-TeCDF generated from chlorine bleaching to the total amount of 2, 3, 7, 8-TeCDF detected in an effluent sample obtained from pulp and paper mill ${ }^{16)}$. Among dioxins isomers, the amount of 2, 3, 7, 8-TeCDF originating from chlorine bleaching was estimated by this proportion. In this study, the sum of this estimated amount and the amount of 2, 3, 7, 8-TeCDD, which was characteristically generated from chlorine bleaching, was described as chlorine bleaching origin in this study.

\section{Results and discussion}

\subsection{Amount of dioxins emission}

3.1.1 Comparison of amounts of dioxins emission from effluents of world pulp mills

Table 1 lists the amounts of dioxins emission from the effluents of world pulp mills. European Union (EU) reported the detailed statement of dioxins emission from Sweden $^{17), 18}$. The amount of the emission was $15 \sim 30 \mathrm{~g}-$
Table 1 Dioxin emission levels in four countries

\begin{tabular}{|c|c|c|c|}
\hline country & year & Releases*(g-TEQ/year) & reference \\
\hline \multirow[t]{3}{*}{ Sweden } & 1987 & $15-30$ & \multirow[t]{3}{*}{$17,18)$} \\
\hline & 1992 & 2 & \\
\hline & 1995 & $1-2$ & \\
\hline \multirow[t]{3}{*}{ US } & 1987 & 370 & \multirow[t]{3}{*}{$19,20)$} \\
\hline & 1995 & 30 & \\
\hline & 2000 & 1.1 & \\
\hline \multirow[t]{2}{*}{ Canada } & 1988 & 270 & \multirow[t]{2}{*}{ 21) } \\
\hline & 1998 & 2 & \\
\hline \multirow[t]{3}{*}{ Japan } & 1997 & 0.74 & \multirow[t]{3}{*}{ 22) } \\
\hline & 2001 & 0.98 & \\
\hline & 2008 & 0.27 & \\
\hline
\end{tabular}

Releases* : Releases from pulp mills in a country

TEQ/year in 1987 when the conversion to ECF and TCF bleachings was initiated. It was reduced to $1 \sim 2 \mathrm{~g}-\mathrm{TEQ} /$ year in 1995 when the conversion was completed. The United States Environmental Protection Agency (EPA) reported the detailed statement of dioxins emission from $\mathrm{USA}^{19,20)}$. The amount of dioxins emission was $370 \mathrm{~g}-$ TEQ/year in 1987 when the conversion to ECF bleaching was not initiated, but it was reduced to about $1.1 \mathrm{~g}$-TEQ/ year in 2000 when the conversion was completed by $95 \%$. The Alliance for Environmental Technology (AET) reported the detailed statement of dioxins emission from Canada $^{21)}$. The amount of the emission before the conver- 
sion to ECF bleaching was $270 \mathrm{~g}$-TEQ/year in 1997, but it was reduced to $2 \mathrm{~g}-\mathrm{TEQ} /$ year after the conversion in 2000 . The Ministry of the Environment reported the detailed statement of dioxins emission from Japan ${ }^{22}$. The amount of the emission was already small $(0.74 \sim 0.98 \mathrm{~g}-\mathrm{TEQ} /$ year $)$ before the conversion to ECF bleaching in 1997 2001. This level was as low as that after the conversion to ECF bleaching in Europe and North America. This low emission level is considered to be because before the conversion to ECF bleaching Japanese pulp mills already took several measures for the suppression of dioxins formation, such as introducing oxygen delignification, active sludge treatment into effluent treatment process, etc., utilizing AOX as an index of dioxins formation ${ }^{5}$. The amount of dioxins emission from Japan after the conversion to ECF bleaching was estimated to be $0.27 \mathrm{~g}$-TEQ/year in 2008 when about $90 \%$ of pulp was produced by ECF bleaching.

3.1.2 Amount of dioxins emission from total effluent

Fig. 3 shows the rough estimates of the total amounts of dioxins emission from the total effluents of 14 mills of Oji Paper Co. Ltd. and Nippon Paper industries Co. Ltd. On the basis of the amount of the total effluent from each of 14 mills and the concentration of dioxins in it, the annual total amounts of dioxins formation from each mill before and after the conversion to ECF bleaching were separately added up for 14 mills, and the result is shown in Fig. 3. In this estimation, annual mill operation was assumed to be 360 days. (The breakdowns of the dioxin isomers generated from chlorine bleaching are also shown in Fig. 3.)

The total amount of dioxins emission from the total effluents of 14 mills was $0.45 \mathrm{~g}$-TEQ/year before the conversion to ECF bleaching, while it was reduced to $0.04 \mathrm{~g}-$ TEQ/year after the conversion. Dioxins emission originating from chlorine bleaching was reduced to the $1 / 30$ level, from 0.2 to $0.007 \mathrm{~g}-\mathrm{TEQ} /$ year, by the conversion to ECF bleaching. These results clarified the effect of the conversion to ECF bleaching on total effluent.

\subsection{Concentration of dioxins in total effluent}

As described above, the total amount of dioxins emission from the total effluents of 14 mills was significantly reduced by the conversion to ECF bleaching. The concentra-

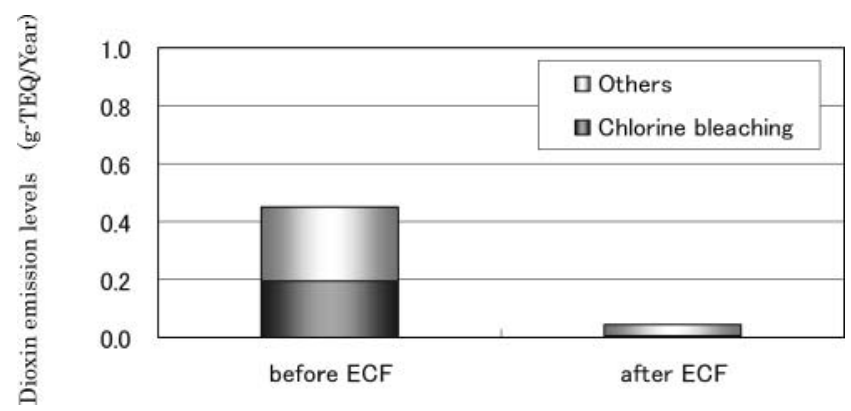

Fig. 3 Dioxin emission levels in total effluent of 14 mills tion of dioxins in the total effluents is described in this section.

Generally in an environmental analysis for regulation of effluent, it is legally required to quantify the concentration of a target compound at the level as low as $1 / 10$ of the regulation value. When the detected level is lower than this $1 / 10$ level, the result is generally expressed as 'not detectable'. In an analysis for dioxins based on the environmental regulation for public waters $(1 \mathrm{pg}-\mathrm{TEQ} / \mathrm{L})$, the concentration of $0.1 \mathrm{pg}-\mathrm{TEQ} / \mathrm{L}$ corresponds to this 'not detectable' level.

Fig. 4 shows the concentrations of dioxins in the total effluents of 14 mills, which is expressed as the toxicity equivalency quantity, pg-TEQ/L. All the concentrations examined before the conversion to ECF bleaching were already lower than the regulation value for concentration of effluent from a mill that was designated as a specified facility by the Law Concerning Special Measures Against Dioxins (10 pg-TEQ/L). Among these 14 mills, the concentrations in 10 mills were even lower than the environmental regulation for public waters $(1 \mathrm{pg}-\mathrm{TEQ} / \mathrm{L})$. Furthermore in 3 mills among these 10 mills, the concentrations were lower than the 'not detectable' level $(0.1 \mathrm{pg}-$ TEQ/L).

The concentrations of dioxins were reduced to be lower than the 'not detectable' level $(0.1 \mathrm{pg}-\mathrm{TEQ} / \mathrm{L})$ in 11 mills among 14 mills just after the conversion to ECF bleaching. The concentrations in the other 3 mills were also reduced to be lower than $1 \mathrm{pg}-\mathrm{TEQ} / \mathrm{L}$. Because the isomers of dioxins that characteristically originate from chlorine bleaching and agrochemicals were not detected in these 3 mills, the origin was considered to be combustion. The treatment process of effluent was further improved after the conversion to ECF bleaching, and consequently, the concentrations of dioxins in 13 mills among 14 mills were lower than the 'not detectable' level (0.1 pg-TEQ/L). The

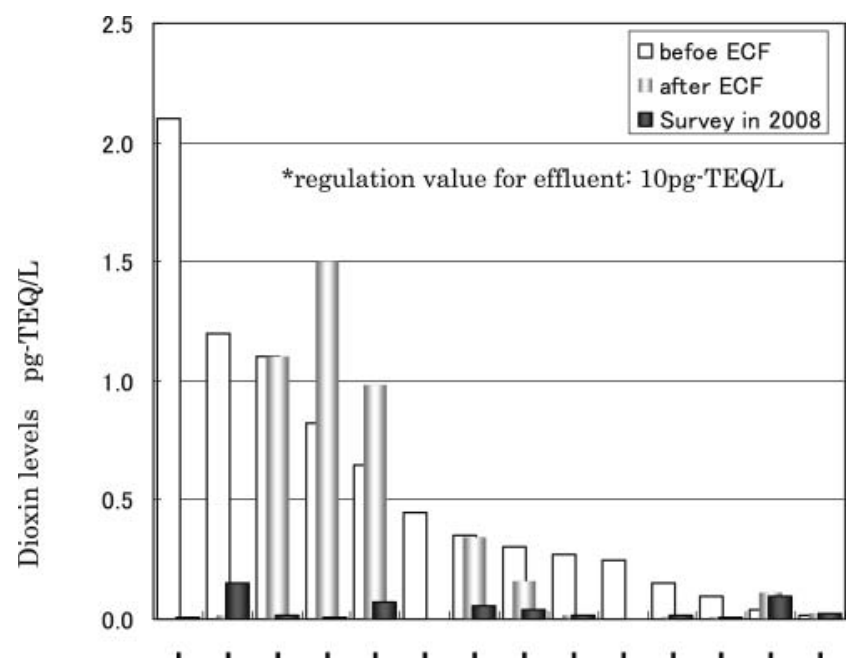

Fig. 4 Dioxin levels in total effluent 
concentration in the other mill was $0.15 \mathrm{pg}-\mathrm{TEQ} / \mathrm{L}$.

It was clarified by these investigations that the concentrations of dioxins in the total effluents were significantly reduced by the conversion to ECF bleaching and became lower than the environmental regulation for public waters, $1 \mathrm{pg}-\mathrm{TEQ} / \mathrm{L}$, in all the 14 mills.

\section{3 Total amount of dioxins formation in bleaching} process

Fig. 5 shows the total amounts of dioxins generated in 18 bleaching lines. Both process water for bleaching and bleached pulp were analyzed to examine the amount of dioxins generated in bleaching process. On the basis of the amount of the process water and the concentration of dioxins in it as well as bleached pulp, the total amount of dioxins annually generated from each of 18 bleaching lines was calculated before and after the conversion to ECF bleaching, and the amounts calculated before and after the conversion to ECF bleaching were separately added up for 18 bleaching lines. Annual mill operation was assumed to be 360 days.

The total amount of dioxins formation was reduced from $20 \mathrm{~g}$-TEQ/year to about the 1/19 level, $1.2 \mathrm{~g}$-TEQ/year, by the conversion to ECF bleaching. The distribution of dioxins to process water and bleached pulp was not changed by the conversion to ECF bleaching.

\subsection{Concentration of dioxins in process water for bleaching}

In the investigation of the formation mechanism and actual dioxins emission enforced in 1999, it was presumed that a trace amount of dioxins detected in ECF bleaching process was attributed to the presence of a small amount

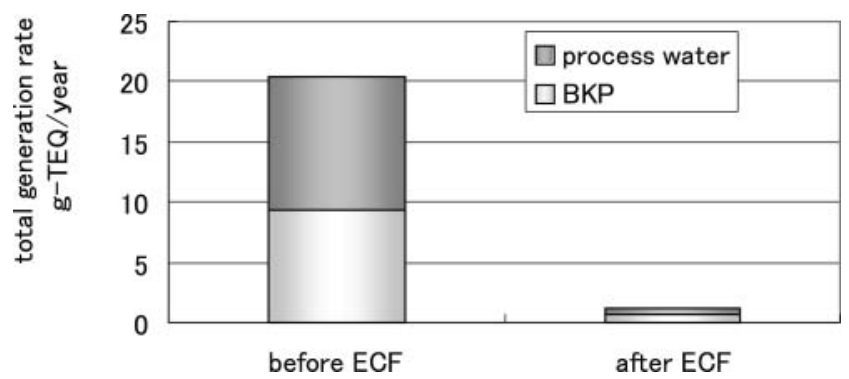

Fig. 5 Dioxin generation levels in pulp and process water of chlorine remaining in the production process of chlorine dioxide ${ }^{7)}$.

The histogram of the concentration of dioxins in the process waters for $\mathrm{C}^{-}$, $\mathrm{D}^{-}$, or $\mathrm{Z}$-stage is shown in the left of Fig. 6. The concentrations in the process waters for $\mathrm{C}^{-}$ stage obtained from 8 bleaching lines among 18 lines were already lower than the environmental regulation for public waters, $1 \mathrm{pg}-\mathrm{TEQ} / \mathrm{L}$, even before the conversion to ECF bleaching. The concentrations in the process waters for $\mathrm{D}^{-}$or Z-stage significantly decreased after the conversion to ECF bleaching, and those obtained from 16 bleaching lines among 18 lines were lower than the environmental regulation for public waters, $1 \mathrm{pg}-\mathrm{TEQ} / \mathrm{L}$. The concentration was $2.2 \mathrm{pg}-\mathrm{TEQ} / \mathrm{L}$ before the conversion and reduced to the $1 / 20$ level, 0.11 pg-TEQ/L, after the conversion, when compared between the medians.

The histogram of the concentration of dioxins in the process waters for $\mathrm{E}^{-}$-stage is shown in the right of Fig. 6 . Although it was considered that dioxins were generated from $\mathrm{C}^{-}$- or $\mathrm{D}^{-}$-stage, the amount of dioxins detected was larger in the process waters for the subsequent $\mathrm{E}$-stage than that for the $\mathrm{C}^{-}$or $\mathrm{D}^{-}$-stage. This should be because generated dioxins were adsorbed on pulps and then desorbed to process water under alkaline conditions in the subsequent $\mathrm{D}^{-}$-stage.

In the process waters for $\mathrm{E}^{-}$-stage of 2 bleaching lines among 18 lines, the concentration of dioxins were already lower than the environmental regulation for public waters, $1 \mathrm{pg}-\mathrm{TEQ} / \mathrm{L}$, even before the conversion to ECF bleaching. After the conversion, the concentrations of dioxins in the process waters for $\mathrm{E}^{-}$-stage were significantly reduced, and those of 10 bleaching lines among 18 lines were lower than the environmental regulation for public waters, $1 \mathrm{pg}-$ TEQ/L. The concentration was $26 \mathrm{pg}-\mathrm{TEQ} / \mathrm{L}$ before the conversion and reduced to about the $1 / 30$ level, $0.8 \mathrm{pg}-$ TEQ/L, after the conversion, when compared between the medians.

It was considered that the amount of chlorine used was already reduced for decreasing the bleaching load before the conversion to ECF bleaching. This decrease in the bleaching load was attained by the improvement of oxy-
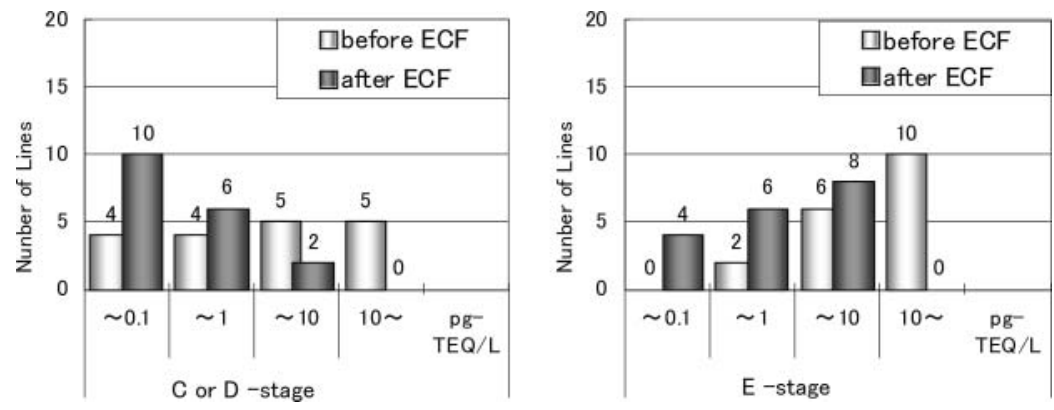

Fig. 6 Dioxin levels in bleaching process water 
gen delignification, which was a correspondence to the requirement for the suppression of AOX as an index of dioxins formation. It was reported that dioxins formation is suppressed when the amount of chlorine used is small ${ }^{4)}$. The concentrations of dioxins in the process waters for 2 bleaching lines were 0.98 and $0.42 \mathrm{pg}-\mathrm{TEQ} / \mathrm{L}$ even before the conversion to ECF bleaching, which were lower than the environmental regulation for public waters, $1 \mathrm{pg}-$ TEQ/L. The amount of chlorine addition was possibly small in these bleaching lines, and consequently, the conditions were unsuitable for the formation of dioxins.

\subsection{Situation of generation of dioxins discharged with bleached pulp}

The concentrations of dioxins in the bleached pulps before and after the conversion to ECF bleaching are compared in Fig. 7. The concentration in the LBKP was in the range between 0.025 and $3.9 \mathrm{pg}-\mathrm{TEQ} / \mathrm{g}$ before the conversion to ECF bleaching. The concentrations in NBKP (1. $1 \mathrm{pg}-\mathrm{TEQ} / \mathrm{g})$ were higher than those in $\operatorname{LBKP}(0.6 \mathrm{pg}-$ $\mathrm{TEQ} / \mathrm{g}$ ), when compared between the medians before the conversion. The concentrations in the bleached pulps obtained from some mills were found to be lower than the level of $0.1 \mathrm{pg}-\mathrm{TEQ} / \mathrm{g}$.

The concentration of dioxins in the bleached pulps was reduced to about the $1 / 50$ level by the conversion to ECF bleaching, and in the range between 0.00024 and $0.24 \mathrm{pg}-$ TEQ/g. The median was $0.01 \mathrm{pg}-\mathrm{TEQ} / \mathrm{g}$. The formation of the dioxins isomers, 2, 3, 7, 8-TeCDD and 2, 3, 7, 8$\mathrm{TeCDF}$, that were characteristic as those originating from chlorine bleaching was largely suppressed, because chlorine was displaced with other chemicals in bleaching process. When a tiny amount of dioxins is detected in bleached pulps even after the conversion to ECF bleaching, these dioxins originate from agrochemicals and combustion ${ }^{8}$.

\section{Summary}

Our research institute has examined the influence of the conversion to ECF bleaching on effluents from mills of Oji Paper Co. Ltd. and Nippon Paper Industries Co. Ltd., and investigated chlorine related compounds, such as EOX, AOX, organic chlorine compounds (chlorophenol etc.), and dioxins, which were contained in various kinds of effluents and pulps before and after the conversion to ECF bleaching.

The amount of dioxins emission before the conversion to ECF bleaching in Japan was the same level as those after the conversion in Europe and USA. This is considered to result from taking measures to suppress formation of dioxins, such as the introductions of oxygen delignification and active sludge treatment in effluent treatment step even
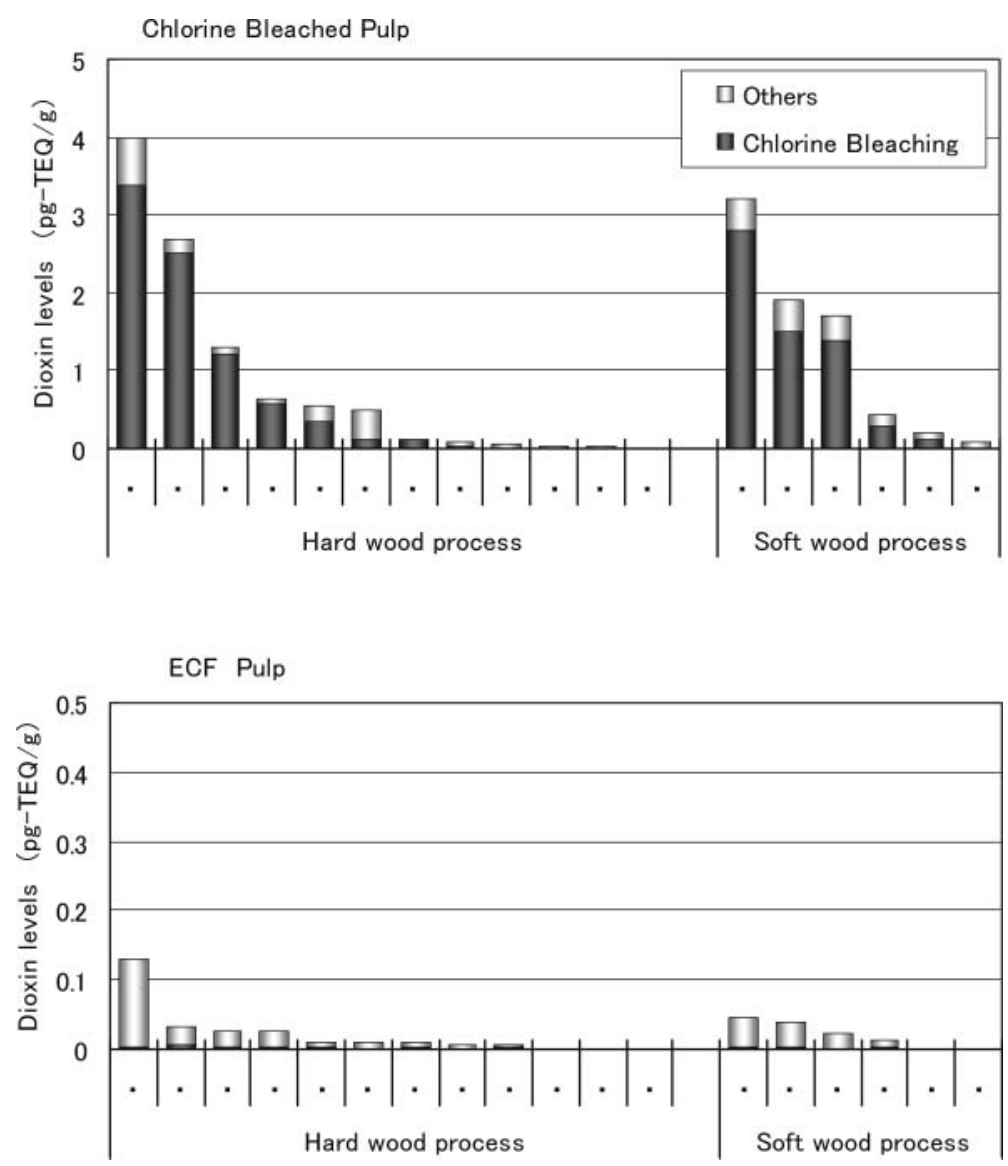

Fig. 7 Dioxin levels in bleached pulps 
before the conversion to ECF bleaching, applying AOX as an index. Furthermore, the annual amount of dioxins emission from 14 mills was reduced from $0.45 \mathrm{~g}-\mathrm{TEQ} /$ year to less than the 1/10 level, $0.04 \mathrm{~g}-\mathrm{TEQ} /$ year, by the conversion to ECF bleaching.

It was considered that a tiny amount of dioxins detected in total effluents just after the conversion to ECF bleaching originated from combustion facility. Due to the reinforcement of effluent treatment process in mills, the concentration of dioxins in the effluents from the mills of Oji Paper Co. Ltd. and Nippon Paper Industries Co. Ltd. is currently much lower than the regulation for effluent, $10 \mathrm{pg}-$ TEQ/L, and even lower that the environmental regulation for public waters, $1 \mathrm{pg}-\mathrm{TEQ} / \mathrm{L}$. Furthermore, the concentrations of dioxins in the total effluents from 13 mills among 14 mills investigated were lower than the $1 / 10$ level of the environmental regulation for public waters, $0.1 \mathrm{pg}-\mathrm{TEQ} / \mathrm{L}$.

Concerning generation of dioxins, the concentrations of dioxins in the process waters for bleaching became lower than the regulation for effluent, $10 \mathrm{pg}-\mathrm{TEQ} / \mathrm{L}$, by the conversion to ECF bleaching. The concentrations were even lower than the environmental regulation for public waters, $1 \mathrm{pg}-\mathrm{TEQ} / \mathrm{L}$, in 9 bleaching lines among 18 lines investigated. The concentration in the ECF bleached pulps was the 'not detectable' level, $0.01 \mathrm{pg}-\mathrm{TEQ} / \mathrm{g}$, as the median. This resulted from the replacement of chlorine with other chemicals in bleaching and the consequent suppression of the formation of dioxins.

Thus, the formation of dioxins from bleaching process of 14 mills of Oji Paper Co. Ltd. and Nippon Paper Industries Co. Ltd. already came unrecognizable. Moreover, dioxins emission from total effluent almost came undetectable. The level of dioxins emission in these mills is now the most excellent in the world.

\section{References}

1) Swanson, S. E., Rappe, C., Malmstrom, J., Kingstad, K. P. : Chemosphere 17 (4) 681 (1988)

2) Ryan, J. J., Panopio, L. G. and Lewis, D. A. In DIOXIN' 88, The 8 th International Symposium on chlorinated Dioxins and Related Compounds, 1988, August 21-26. Umea, Sweden.

3) Wakimoto, et al., Symposium of Environmental Science, Japan, (1988)

4) Luthe, C. E., Wrist, P. E. and Berry, R. M. : Pulp \& Paper Canada, 93 (9) 40 (1992)
5) Takagi H. and Nakagawa M. : Japan Tappi J. 63 (9) 1091 (2009)

6) Iwata H. : Japan Tappi J. 63 (10) 1225 (2009)

7) "Study report for controling environmental loading substances (study of the generation mechanism and the effluent actual conditions of dioxins by ECF). 2000 fiscal year", Japan Environmental Management Association for Industry (2001)

8) Toyota, K., et al. : Pulp and Paper Research conference proceedings, JAPAN TAPPI, Tokyo, 2002 p 120

9) Wiberg, K., Lundstrom, K., Glas, B. and Rappe, C. : Chemosphere, 19, 735 (1989)

10) Ohi, H., Hosoya, S. and Magara, K. : Japan Tappi. J. 56 (8) 1184 (2002)

11) Ohi, H. : Japan Tappi J. 56 (9) 1325（2002）

12) Luthe, CE. : Chemoshere 36 (2) 225 (1998)

13) Seike, N., et al. : J Environmental Chemistry 13 (1) 117 (2003)

14) Hashimoto, S., et al. : J Environmental Chemistry 15 (4) 813 (2005)

15) Sasaki, Y., et al. : J. Environmental Chemistry, 17, 27 (2007)

16) Jikibara, T., et al. : Pulp and Paper Research conference proceedings, JAPAN TAPPI, Tokyo, 2007 p 110

17) Standardized toolkit for Identification and Quantification of Dioxin and Furan Releases, p 142, United Nations Environment Programme, UNEP/POPS/COP. 2/INF/11, 2006

18) European Dioxin Inventory-Volume 2 http://ec.europa.eu/environment/dioxin/pdf/stage $1 /$ inv_s.pdf

19) The Inventory of Sources of Dioxins in the United States-REVIEW DRAFT-EPA/600/P-98/002 Aa, 840, US-EPA 1998

20) US EPA “An Inventory of Sources and Environmental Releases of Dioxin-Like Compounds in the United States for the Years 1987, 1995, and 2000" http://www.epa.gov/ncea/pdfs/dioxin/2k-update/

21) Alliance for Environmental Technology “ECF : The Sustainable Technology Quality Paper Clean Environment (2009)" http://www.aet.org/epp/ecf_brochure.pdf

22) Government of Japan “Dioxins”, 2009 http://www.env.go.jp/en/chemi/dioxins/brochure 2009.pdf

(Manuscript accepted 15 June, 2012) 